Review

\title{
Titanium Nitride and Nitrogen Ion Implanted Coated Dental Materials
}

\author{
Youssef S. Al Jabbari ${ }^{1}$, Jennifer Fehrman ${ }^{2}$, Ashley C. Barnes ${ }^{2}$, Angela M. Zapf ${ }^{3}$, \\ Spiros Zinelis ${ }^{1,4}$ and David W. Berzins ${ }^{1,3, *}$
}

1 Dental Biomaterials Research and Development Chair, College of Dentistry, King Saud University, Riyadh 11545, Saudi Arabia; E-Mail: yaljabbari@ksu.edu.sa

2 School of Dentistry, Marquette University, Milwaukee, WI 53233, USA;

E-Mails: jennifer.fehrman@marquette.edu (J.F.); ashley.barnes@marquette.edu (A.C.B.)

3 Dental Biomaterials, School of Dentistry, Marquette University, Milwaukee, WI 53233, USA;

E-Mail: angela.zapf@marquette.edu

4 Department of Biomaterials, School of Dentistry, University of Athens, Athens, Greece;

E-Mail: szinelis@dent.uoa.gr

* Author to whom correspondence should be addressed; E-Mail: david.berzins@marquette.edu; Tel.: +1-414-288-5690; Fax: +1-414-288-6393.

Received: 4 May 2012; in revised form: 2 July 2012 / Accepted: 3 July 2012 /

Published: 26 July 2012

\begin{abstract}
Titanium nitride and/or nitrogen ion implanted coated dental materials have been investigated since the mid-1980s and considered in various applications in dentistry such as implants, abutments, orthodontic wires, endodontic files, periodontal/oral hygiene instruments, and casting alloys for fixed restorations. Multiple methodologies have been employed to create the coatings, but detailed structural analysis of the coatings is generally lacking in the dental literature. Depending on application, the purpose of the coating is to provide increased surface hardness, abrasion/wear resistance, esthetics, and corrosion resistance, lower friction, as well as greater beneficial interaction with adjacent biological and material substrates. While many studies have reported on the achievement of these properties, a consensus is not always clear. Additionally, few studies have been conducted to assess the efficacy of the coatings in a clinical setting. Overall, titanium nitride and/or nitrogen ion implanted coated dental materials potentially offer advantages over uncoated counterparts, but more investigation is needed to document the structure of the coatings and their clinical effectiveness.
\end{abstract}


Keywords: titanium nitride; nitrogen ion implantation; dental materials; implants; endodontics; orthodontics; dental instruments

\section{Introduction}

Titanium nitride (TiN) and nitrogen ion implanted coatings have been used in industry for quite some time with eventual cross-over to dental applications in the mid-1980s. Since this time, these coatings have been applied to dental materials used in implant dentistry, orthodontics, endodontics, prosthodontics, and periodontics. Depending on application, the purpose of the coating is to provide increased surface hardness, abrasion/wear resistance, and corrosion resistance, lower friction, as well as greater beneficial interaction with adjacent biological and material substrates. A review of titanium nitride coatings in clinical dentistry was published in 1992 by Mezger and Creugers [1]. Taking into consideration that much has changed in dentistry and coating technology since 1992, the objective of this article was to provide a review of the literature of titanium nitride and nitrogen-ion implanted coated dental materials, focusing on coating methodologies, structural analysis, and an examination of coating applications and properties in the aforementioned disciplines.

\section{Coating Methodologies and Structural Analysis}

A myriad of methodologies have been used to create TiN and nitrogen ion implanted coatings in various dental materials. A compilation of the methodologies as listed in the literature is displayed in Table 1. It is possible some subcategory methodologies are the same since the methodology to coat the dental materials was not always explicitly detailed or common nomenclature was not used. Still, it is apparent the majority of methodologies used are of the physical vapor deposition (PVD) type while thermal nitriding and chemical vapor deposition were employed in only 3 and 4 studies, respectively. Approximately 20 studies did not list the way in which the coating was deposited. A possible reason for this is that the coating may have been on a commercial product; thus the method/details of deposition may remain proprietary or are not published in manufacturer literature. Additionally, the coating was not the main focus of a few studies so details were understandably lacking. Coating methodology was contained in all of the Endodontic and Prosthodontic literature reviewed below as the coatings were more likely to be experimental in nature and certain properties were investigated, whereas it was less likely to be mentioned in the Dental Implant and Orthodontic literature; for the latter, commercial products were commonly evaluated.

Structural analysis, in the form of determining composition or phase structure of the coatings, was only used in a minority of studies (Table 1). Three methods were used to identify composition and/or phase structure: X-Ray Photoelectron Spectroscopy (XPS), X-Ray Diffraction (XRD), and Nuclear Reaction Analysis. XPS was used for detailed surface composition analysis. Often the N/Ti ratio was determined to indicate the amount of $\mathrm{N}$ deposition in the coating and to determine whether the ratio corresponded to stoichiometric values. Additionally, alternating XPS with sputter etching allowed depth profiles to be generated. XRD was used to identify the crystal structure of the coatings. A majority of studies that used XRD ( 5 of 8 in Table 1 ) identified only TiN, whereas TiN with $\mathrm{Ti}_{2} \mathrm{~N}$ was 
identified only once. Oxynitrides were also mentioned, but definitive identification was lacking. Nuclear Reaction Analysis was used in two studies to determine the concentration of nitrogen as a function of depth.

Table 1. Compilation of coating methods, structural (composition and phase) analysis methodology, and coating thickness listed in the various dental materials literature.

\begin{tabular}{|c|c|c|}
\hline Coating Method & Type/Detail & Reference \\
\hline Physical Vapor Deposition & $\begin{array}{l}\text { No further detail beyond "Physical Vapor } \\
\text { Deposition" } \\
\text { Ion Plating } \\
\text { Cathodic Arc } \\
\text { Radiofrequency sputtering } \\
\text { Arc ion plating } \\
\text { Plasma immersion implantation } \\
\text { Ion beam/Ionic implantation }\end{array}$ & $\begin{array}{l}{[2-7]} \\
{[8-14]} \\
{[15-19]} \\
{[20-27]} \\
{[28-31]} \\
{[32-34]} \\
{[8,9,35-42]}\end{array}$ \\
\hline Thermal & $\begin{array}{l}500^{\circ} \mathrm{C} \text { for } 480 \mathrm{~min} \\
850^{\circ} \mathrm{C} \text { for } 7 \mathrm{~h} \\
800-1000^{\circ} \mathrm{C} \text { for } 5-30 \mathrm{~min}\end{array}$ & $\begin{array}{l}{[35]} \\
{[43]} \\
{[44,45]}\end{array}$ \\
\hline Chemical Vapor/Chemical & $\begin{array}{l}\text { Reaction of wet } \mathrm{NH}_{3} \text { with } \mathrm{NiTi} \text { at } 300{ }^{\circ} \mathrm{C} \\
\text { MOCVD (metal organic chemical vapor } \\
\text { deposition) via evaporation of } \mathrm{Ti}\left(\mathrm{Et}_{2} \mathrm{~N}\right)_{4} \\
\text { Plasma chemical vapor } \\
\text { Boiling in } 30 \% \text { nitric acid for } 24 \mathrm{~h}\end{array}$ & $\begin{array}{l}{[46]} \\
{[28,46]} \\
{[38]} \\
{[34]}\end{array}$ \\
\hline No method stated & & {$[47-68]$} \\
\hline Structural Analysis & Comment & Reference \\
\hline $\begin{array}{l}\text { X-Ray Photoelectron } \\
\text { Spectroscopy (XPS) }\end{array}$ & $\begin{array}{l}{[\mathrm{N}],[\mathrm{Ti}] \text {, and sometimes other elements and ratios }} \\
\text { determined }\end{array}$ & $\begin{array}{l}{[3,28,29} \\
32-35,46]\end{array}$ \\
\hline X-Ray Diffraction (XRD) & $\begin{array}{l}\mathrm{TiN} \text { and } \mathrm{Ti}_{2} \mathrm{~N} \text { Identified } \\
\text { Unidentified oxynitrides }\end{array}$ & $\begin{array}{l}{[27,29,30} \\
42,67] \\
{[43]} \\
{[44,45]}\end{array}$ \\
\hline Nuclear Reaction Analysis & {$[\mathrm{N}]$ depth } & {$[36,37]$} \\
\hline $\begin{array}{l}\text { Method to Determine } \\
\text { Coating Thickness }\end{array}$ & Thickness & Reference \\
\hline $\begin{array}{l}\text { Scanning Electron Microscopy } \\
\text { (SEM) }\end{array}$ & $\begin{array}{l}1-2 \mu \mathrm{m} \\
2 \mu \mathrm{m} \\
\sim 10 \mu \mathrm{m}\end{array}$ & $\begin{array}{l}{[29]} \\
{[20,43]} \\
{[44,45]}\end{array}$ \\
\hline $\begin{array}{l}\text { Electron Probe MicroAnalysis } \\
\text { (EPMA) }\end{array}$ & $0.3 \mu \mathrm{m}$ average & {$[26]$} \\
\hline
\end{tabular}


Table 1. Cont.

\begin{tabular}{lll}
\hline \multicolumn{1}{c}{$\begin{array}{c}\text { Method to Determine } \\
\text { Coating Thickness }\end{array}$} & \multicolumn{1}{c}{ Thickness } & Reference \\
\hline XPS & {$[\mathrm{N}]_{\text {max }}$ within $10 \mathrm{~nm}$; [N] detected up to } & {$[35]$} \\
& $60 \mathrm{~nm}$ depth & \\
Nuclear Reaction Analysis & {$[\mathrm{N}]$ detected up to $60 \mathrm{~nm}$} & {$[36,37]$} \\
Ball-cratering method & $1.5 \mu \mathrm{m}$ & {$[21]$} \\
Light Microscopy & $8 \mu \mathrm{m}$ & {$[67]$} \\
\hline & $<650 \mathrm{~nm}$ & {$[40]$} \\
& $0.3 \mu \mathrm{m} \mathrm{N}$-implanted; $3 \mu \mathrm{m}$ TiN & {$[8,9]$} \\
Given via a reference, & $1 \mu \mathrm{m}$ & {$[27]$} \\
manufacturer data, equipment & $1.5 \mu \mathrm{m}$ & {$[17,18]$} \\
parameters, or other & $1.8 \mu \mathrm{m}$ & {$[22-25]$} \\
unconfirmed sources & $2 \mu \mathrm{m}$ & {$[14,42]$} \\
& $1-5 \mu \mathrm{m}$ & {$[15]$} \\
& $2-5 \mu \mathrm{m}$ & {$[47]$} \\
& $10 \mu \mathrm{m}$ & {$[19]$} \\
\hline
\end{tabular}

Using these forms of structural analysis, it is apparent that the different coating methodologies will impart different deposition of nitrogen in terms of amount and depth, as also documented by others $[28,32,35,46]$. Even different parameters within a given coating technology will affect nitrogen distribution [36]. Overall, structural analysis of the coatings in the dental materials literature is lacking in a majority of studies.

The thickness of the TiN and nitrogen ion implanted coatings are also compiled in Table 1 . The majority of studies list the coating thickness as between $1 \mu \mathrm{m}$ and $5 \mu \mathrm{m}$ although the range is anywhere from $0.06 \mu \mathrm{m}$ to $10 \mu \mathrm{m}$. Scanning Electron Microscopy (SEM) was used most frequently to determine coating thickness; also employed were XPS and Nuclear Reaction Analysis as mentioned above, as well as Electron Probe MicroAnalysis (EPMA), light microscopy, and the ball-cratering method. However, it was most common to cite the thickness of coating via reference, manufacturing data, based upon equipment parameters, or other unspecified sources instead of actual measurement. Since the thickness of coatings produced by the methodologies listed in Table 1 are sensitive to various parameters (e.g., time and temperature for thermal nitridation), specifically measuring the coating thickness would seem to be the best practice.

Although the majority of analyses document more of a monolithic coating, it is likely the coatings exist as complex, layered structures. Certainly, the nitrogen concentration depth profiles may suggest this $[28,32,35-37,46]$. Additionally, several researchers observed multiple layers, whether intentionally deposited to increase adherence of the coating, a by-product of the coating process, or natural as in the form of titanium's passive oxide layer. For instance, Chung et al. [20] and Kurt et al. [21] used an intermediate layer of sputter coated $\mathrm{Ti}$ and $\mathrm{Al}$ before adding nitrogen to improve adhesion of layers on the substrate. On the other hand, Iijima et al. [33] observed $\mathrm{TiO}_{2}$ on the surface covering a TiN layer on nickel-titanium (NiTi) wires via XPS, presumably due to the natural passivation of titanium. 
Similarly, Endo et al. [29] showed a trilayer composed of $\mathrm{TiO}_{2}$ on the outside, a middle layer of $\mathrm{TiN}_{x}$ $(x>1)$, and an inner layer of $\mathrm{TiN}$.

\subsection{Coatings in Implant Dentistry}

The clinical efficacy of dental implants depends on many different factors related to the bulk and surface properties of the dental implant materials and their components. Recently, the application of nitride coatings on $\mathrm{Ti}$ and its alloys have been proposed as a surface treatment aiming to increase the mechanical, physical, and esthetic properties of dental implants. Generally, nitride coatings, by a factor of approximately 10, increase the surface hardness [43,47], wear resistance [47], and corrosion resistance $[29,43]$ of implant materials. Additionally beneficial, coated Ti surfaces have also been connected with antimicrobial properties [8,9]. Nitride coatings specific to dental implant materials have been prepared mainly by Physical Vapor Deposition methods, with the exception of Tamura et al. [43] who used a thermal treatment, with measured thicknesses ranging between $1 \mu \mathrm{m}$ and $2 \mu \mathrm{m}[21,29,43]$.

Bacterial adherence to the implant surface is associated with the pathogenesis of bacterial infections leading to implant loss. The implant abutment is exposed in the oral environment and so dental calculus and plaque can be readily developed. However, the calculus and plaque should be periodically removed to obtain a good prognosis throughout the lifetime of the dental implant. In light of this, antibacterial activity is a desirable property while, especially for the abutment, enhanced abrasion resistance against scaling treatments is wanted to maintain the surface finish of the abutment. However, surface coatings have been shown to be prone to detachment after just a few actions with $\mathrm{Ti}$ and stainless steel dental instruments [15].

Three in vitro research studies assessed the antibacterial activity of TiN coatings and concluded that there is no difference between $\mathrm{Ti}$ and nitrified $\mathrm{Ti}$ for adherence of Streptococcus mutans [43], Porphyromonas gingivalis, and Actinobacillus actinomycetemcomitans [8,9]. In contrast, the adherence of Streptococcus mutans and Streptococcus sanguis was significantly reduced on TiN surfaces compared to polished ones [22]. The same favorable results were found for TiN-TPS (titanium plasma sprayed) compared to uncoated TPS where Streptococcus pyogenes and Streptococcus sanguinis bacteria demonstrated decreased bacterial adhesion and proliferation [16]. Two studies based on in vivo data confirmed the positive effect of TiN coating on the antibacterial activity of Ti surfaces. The results of Scarano et al. [2] showed that implants coated with TiN illustrated a minor quantity of the surface covered by bacteria after a 24-h exposure to the oral cavity while a smaller bacterial quantity were found on TiN glass sheets compared to pure Ti coated glass sheets after $60 \mathrm{~h}$ of intraoral exposure [23]. TiN coatings seem to have a beneficial effect on antibacterial activity inhibiting the formation of microbial plaque, minimizing the adverse effects of peri-implantitis on implant longevity. The aforementioned antibacterial activity combined with the wear resistance to scaling treatment points out that the application of TiN coatings to implant abutments holds promise and is worthwhile for further scientific research and optimization.

The introduction of $\mathrm{Ti}$ and its alloys in implant dentistry was based on the osseointegration properties of $\mathrm{Ti}$ oxide (i.e., anchoring of the implant via growth and attachment of bone to the implant). After this breakthrough, research worldwide focused on surface modifications to improve 
and accelerate bone remodeling on Ti surfaces. In vitro and in vivo results show that TiN coatings do not have an adverse effect on this vital property. In vitro studies demonstrated that cell adhesion was no different between coated and uncoated Ti surfaces employing either mouse [24] or human gingival fibroblasts [25], while proliferation of human osteoblasts increased on $\mathrm{TiNO}_{x}$-coated titanium surfaces compared to uncoated controls [3]. Similar results were found by other studies applying bone marrow human mesenchymal stem cells [38] and bone marrow human stromal cells [4]. In vivo tests with animal models were similarly positive. Despite the diversity of experimental methodology, all in vivo data illustrate that bone formation as expressed by Bone Implant Contact (BIC) around coated and uncoated dental implants is similar. Table 2 demonstrates the duration of implantation, the animal model used, and BIC for Ti and TiN-coated materials from several in vivo studies. In yet another in vivo study in rats, the thickness of fibrous connective tissue around Ti-6Al-4V implants was found to be the same whether it was coated with $\mathrm{TiO}_{2}$ or TiN [10]. Based on the above studies, it can be concluded that the TiN coating demonstrates a good biological response and does not negatively affect osseointegration and healing around Ti implants.

Table 2. Duration of implantation, animal model, and Bone Implant Contact (BIC) for several in vivo implant material studies.

\begin{tabular}{cccccc}
\hline \multirow{2}{*}{$\begin{array}{c}\text { Duration } \\
\text { (Weeks) }\end{array}$} & Animal & Prior Surface & \multicolumn{2}{c}{ BIC (\%) } & \multirow{2}{*}{ Reference } \\
\cline { 4 - 5 } & Model & Treatment & Ti & TiN & \\
\hline 8 & Rats & Machining & $59.0 \pm 3.1$ & $58.0 \pm 3.0$ & {$[5]$} \\
8 & Rats & Sandblasting & $64.0 \pm 4.1$ & $66.0 \pm 3.5$ & {$[5]$} \\
8 & Rats & TPS & $72.0 \pm 2.5$ & $70.0 \pm 2.1$ & {$[5]$} \\
8 & Rats & & 42.6 & 40.8 & {$[43]$} \\
8 & Dogs & & $69.7 \pm 1.3$ & $70.6 \pm 1.7$ & {$[48]$} \\
12 & Rabbits & & 58.8 & 52.7 & {$[39]$} \\
\hline
\end{tabular}

Besides abutments and implants, TiN coatings have also been evaluated with other components. TiN coatings may provide enhanced resistance to wear in ball attachments for implant-overdenture systems, significantly increasing their longevity. After 1 year of clinical use, TiN coated attachment systems appeared unchanged while extensive wear was evident in uncoated systems [47]. Wear decreases the retention force of attachments, causing discomfort to the patient and increasing the maintenance needs of removable prosthetic restorations [49]. The last application of TiN coating in implant dentistry is the covering of retentions screws for implant supported crowns [50]. Screws coated with aluminum titanium nitride showed inferior retention of torque, a finding that might be associated with the minimal ductility of the coated screw compared to pure Ti. Thus, aluminum titanium nitride coatings are not recommended for this application.

In conclusion, the application of TiN coating on $\mathrm{Ti}$ implants provides antibacterial activity without compromising the osseointegrative properties of the Ti surface. In addition, it enhances the wear resistance of Ti abutments. Further research appears warranted, especially clinical research to assess the efficacy of the coatings long term. 


\subsection{Coatings in Orthodontics}

During orthodontic treatment, tooth movement is achieved by applying forces to the teeth through the use of brackets, wires and elastics, which in turn result in the remodeling of the alveolus, or tooth socket. It is believed that light, continuous forces are optimal for most effectively and least traumatically moving teeth. The wire most commonly used in the initial leveling phase of treatment is the NiTi archwire, for it is the most elastic and flexible, capable of maintaining the light continuous forces desired. The NiTi alloy typically possesses a composition of $50 / 50$ at $\% \mathrm{Ni} / \mathrm{Ti}$, or approximately $55 \mathrm{wt} \% \mathrm{Ni}$ and $45 \mathrm{wt} \% \mathrm{Ti}$, and was introduced to orthodontics in 1971 [69]. Treatment is typically finished out with $\beta$-titanium and stainless steel (SS) arch wires. $\beta$-titanium was introduced to orthodontics in 1979 [70] and contains Mo to metastabilize a BCC phase to room temperature, along with $\mathrm{Sn}$ and $\mathrm{Zr}$. As a result, this wire was initially introduced by the Ormco Corporation (Glendora, CA, USA) as "TMA" for Titanium Molybdenum Alloy. While all three types of wires are available as originally designed, the NiTi and TMA wires are also available in versions which have undergone an ion implantation process during which nitrogen is implanted into the surface of the wires. The ion implanted TMA has also been known as "low-friction" and is offered in different colors as shown in Figure 1. This ion implantation process provides the NiTi and $\beta$-titanium wires with a coating which has been hypothesized to decrease surface roughness, and thereby decrease frictional forces, to produce more efficient tooth movement, and to reduce corrosion of the NiTi wires by limiting the release of nickel ions from the wire over time. Each of these hypotheses have been tested and documented in the literature. The following will provide an overview of the findings in regards to the effects of coatings applied to NiTi and $\beta$-titanium arch wires.

Figure 1. Ion implanted $\beta$-titanium orthodontic archwires (honeydew and purple).

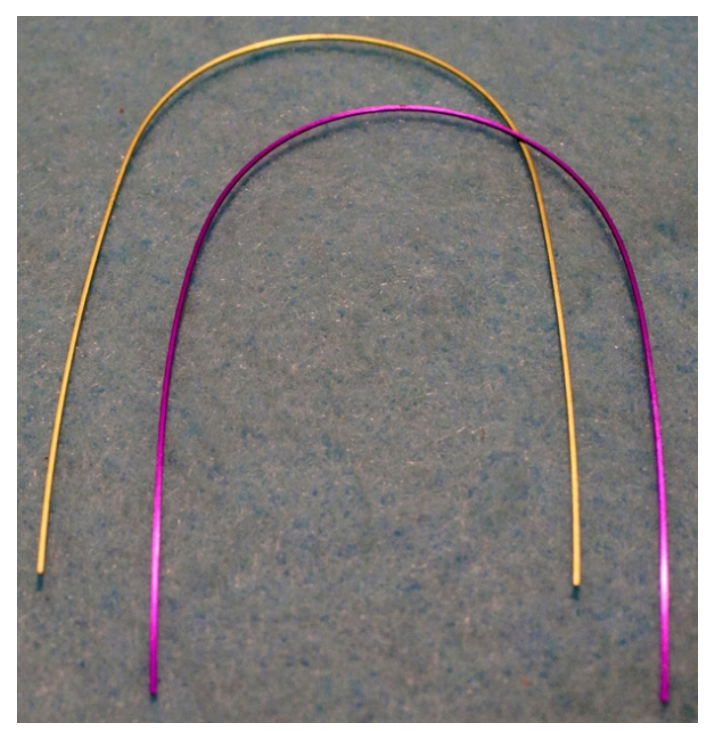

Perhaps the most widely tested hypothesis regarding ion implanted arch wires and/or brackets is whether these coatings have the ability to reduce surface roughness and frictional forces, and by extension, to produce more efficient tooth movement. Six studies [6,40,44,51-53] found that nitrogen implanted NiTi and TMA wires decreased surface roughness, frictional coefficients, or friction force values, although oral exposure may mitigate this initial advantage [51]. Contrastingly, two 
studies [11,54] found that applying coatings made no significant difference in the roughness and/or friction coefficients. Interestingly, another study found coated TMA exhibited increased or decreased static and kinetic friction forces compared to uncoated TMA depending on the color of the coating. This is curious since the TMA products are offered by the same company and presumably would originate from the same wire stock. Table 3 summarizes the effect of nitrogen implantation on friction behavior observed in some of the above orthodontic studies. When coatings did increase friction, the values were generally within $111 \%$ of that exhibited by the control or non-coated wire. However, when the coating decreased friction, values were as low as $20 \%$ of the control. Nonetheless, the stability of the coating in vivo and its ability to continue providing reduced friction is in question as shown by Wichelhaus et al. [51]. Although new wires of coated NiTi (Neo Sentalloy F80 Ionguard) displayed less friction compared to uncoated NiTi (Neo Sentalloy), after 4 weeks of clinical use, friction values were equivalent. Thus, while surface treatments were shown to improve the sliding of the bracket along the arch wire initially, that effect was lost when the wires were exposed to the oral cavity.

Table 3. Effect of nitrogen implantation on friction observed in several in vitro orthodontic studies.

\begin{tabular}{|c|c|c|c|c|}
\hline Wire Type & $\begin{array}{l}\text { Commercial Product Name } \\
\text { (Manufacturer) }\end{array}$ & $\begin{array}{c}\text { Coupled } \\
\text { Material for } \\
\text { Friction } \\
\text { (if specified) }\end{array}$ & $\begin{array}{c}\text { Amount of Friction } \\
\text { Compared to Control } \\
\text { (non-coated } \\
\text { counterpart) } \\
\end{array}$ & Reference \\
\hline $\mathrm{NiTi}$ & & Ti-6Al-4V & $45 \%$ & \multirow{2}{*}[44]{} \\
\hline $\mathrm{NiTi}$ & & Stainless steel & $59 \%$ & \\
\hline $\mathrm{NiTi}$ & $\begin{array}{c}\text { Neo Sentalloy F80 Ionguard } \\
\text { (GAC Int., Bohemia, NY, USA) }\end{array}$ & & $77 \%$ & {$[51]$} \\
\hline$\beta$-titanium & Purple TMA (Ormco) & Stainless steel & $\begin{array}{l}25 \%(\text { static }) \\
20 \%(\text { kinetic })\end{array}$ & [6] \\
\hline$\beta$-titanium & Ion-implanted TMA (Ormco) & $\begin{array}{l}\text { Ti implanted } \\
\text { alumina }\end{array}$ & $\begin{array}{c}47 \% \text { (static) } \\
66 \% \text { (kinetic) }\end{array}$ & {$[40]$} \\
\hline$\beta$-titanium & Ion-implanted TMA (Ormco) & Stainless steel & $\begin{array}{c}100 \% \text { (static) } \\
108 \% \text { (kinetic) }\end{array}$ & {$[54]$} \\
\hline$\beta$-titanium & Aqua TMA (Ormco) & Stainless steel & $\begin{array}{c}105 \% \text { (static) } \\
111 \% \text { (kinetic) }\end{array}$ & \multirow{5}{*}{ [55] } \\
\hline$\beta$-titanium & Honeydew TMA (Ormco) & Stainless steel & $\begin{array}{l}49 \% \text { (static) } \\
55 \% \text { (kinetic) }\end{array}$ & \\
\hline$\beta$-titanium & Purple TMA (Ormco) & Stainless steel & $\begin{array}{l}102 \% \text { (static) } \\
104 \% \text { (kinetic) }\end{array}$ & \\
\hline$\beta$-titanium & Violet TMA (Ormco) & Stainless steel & $\begin{array}{c}96 \% \text { (static) } \\
102 \% \text { (kinetic) }\end{array}$ & \\
\hline$\beta$-titanium & Ion-implanted TMA (Ormco) & Stainless steel & $\begin{array}{c}51 \% \text { (static) } \\
55 \% \text { (kinetic) }\end{array}$ & \\
\hline
\end{tabular}

It has also been hypothesized that the ion implantation process would increase the biocompatibility of NiTi wires by reducing the amount of nickel released during the corrosion process. Seeing as nickel 
allergies are an issue in orthodontics, a reduction in the release of nickel ions would be greatly beneficial. Besides measuring nickel release into a solution, an indirect method of assessing this is to test the corrosion properties of the alloys. As a result, both methods appear in the literature. Of the studies which pertained to the above hypothesis, three $[33,45,56]$ found a coating provided beneficial corrosion property alterations, while three other studies $[12,57,58]$ found the ion implantation process incapable of decreasing the amount of nickel released into the oral environment or providing beneficial corrosion properties. These studies will be briefly summarized below.

NiTi wires treated with a nitrogen diffusion thermal treatment to create a TiN surface layer intended to reduce the corrosion potential of the wires were examined by Gil et al. [45] to measure ion release into an artificial saliva solution. While both the treated and untreated wires showed a high rate of nickel ion release initially, the treated wires ultimately released significantly less than that released by the untreated wires, reaching saturation at a much lower concentration of nickel ions. Iijima et al. [33] studied the corrosion properties of nitrogen ion implanted NiTi wires (Neo Sentalloy Ionguard) compared to non-ion implanted NiTi (Neo Sentalloy). The two wires were examined utilizing potentiodynamic polarization measurements, which were completed in both artificial saliva and a fluoride mouth rinse solution, as it has been hypothesized that the acidic environment created by fluoride may dissolve the TiN coating. Ultimately, it was found that the Neo Sentalloy Ionguard wires had a greater corrosion resistance in both artificial saliva and fluoride mouth rinse solution, despite the slightly more acidic environment that it created. Neumann et al. [56] similarly evaluated nitrogen ion implanted NiTi compared to an uncoated version, as well as two coated TMA wires, via measurement of rupture potentials in artificial saliva. The coating on the TMA wires was stable electrochemically; the coating on NiTi increased its rupture potential by $140 \mathrm{mV}$ and reduced surface destruction when viewed under SEM.

Peitsch et al. [57] measured nickel release from mechanically loaded coated (Neo Sentalloy Ionguard) and uncoated NiTi in ultrapure water and saline. When the wires were subjected to a load, they released significantly more nickel ions, which is important to consider given that arch wires are typically under load in the oral cavity. However, the data could not confirm that surface nitridation reduced the release of nickel ions, whether in a loaded or unloaded state.

Kao et al. [12] conducted a study in which TiN ion implanted stainless steel brackets were analyzed against non-ion implanted stainless steel brackets in regards to corrosion resistance and release of $\mathrm{Ni}$ ions into the oral environment. The TiN coated brackets were shown to release more nickel, chromium, cobalt, manganese, and ferric ions. Copper was the only ion in which the ion implanted brackets released less of than the non-ion implanted brackets. Based on these findings, the authors were able to conclude that the anticorrosion properties of TiN coated brackets are relatively poor; thus no increase in biocompatibility is to be expected.

Kim et al. [58] studied the breakdown potential of the following arch wires: stainless steel, NiTi, nitride-coated $\mathrm{NiTi}$, epoxy-coated $\mathrm{NiTi}$, and titanium in a $0.9 \% \mathrm{NaCl}$ solution of neutral $\mathrm{pH}$ at room temperature. It was determined that the TiN coating on the NiTi wires did not decrease corrosion and did not alter the breakdown potential. The epoxy-coated wire, however, did significantly decrease corrosion. Thus, the authors concluded that for patients with nickel allergies, an epoxy-coated NiTi wire would be recommended so as to reduce the risk of an allergic reaction. 
Schuster et al. [59] determined the allergic potential of orthodontic materials utilized during treatment via questionnaire. While they concluded that the number of patients with allergies to orthodontic materials is likely overestimated, there are still $0.2 \%$ of patients who will show some sort of reaction. Based on the fact that allergies are a possibility, they recommend avoiding materials prone to corrosion, as well as coatings such as titanium nitride, so as not to induce a nickel related allergy. The rationale for the latter recommendation, however, was not well developed.

One additional study, conducted by Pernier et al. [60], analyzed the effects of autoclaving on ion implanted and non-ion implanted wires in regards to the effect of surface structure. Six commonly used wires were analyzed: one stainless steel wire, two NiTi wires (Neo Sentalloy and Neo Sentalloy Ionguard), and three titanium-molybdenum wires (TMA, Low Friction TMA and Resolve). The Low Friction TMA and NeoSentalloy Ionguard are commercially subjected to the ion implantation process. All wires were autoclaved for $18 \mathrm{~min}$ at $134{ }^{\circ} \mathrm{C}$ and examined before and after sterilization with various surface analysis techniques. None of the analyses showed significant changes in the properties of any of the wires after having been autoclaved. Thus, the authors concluded that autoclaving is a safe means of sterilizing arch wires without interfering with or changing the properties of such wires.

Lastly, it has been postulated that coated arch wires have the ability to generate more efficient tooth movement. Likely this finding is an extension of the effect the coatings have on the friction generated between the arch wire and the bracket. Of the studies which specifically analyzed efficiency of tooth movement, one [61] found that wires subjected to the nitrogen ion implantation process produced more efficient tooth movement, while two other studies $[62,63]$ found that the ion implanted arch wires were not able to produce a significantly faster rate of tooth movement.

The following five wires were used by Ryan et al. [61] to test efficiency of tooth movement: $\mathrm{N}$ ion implanted nickel-titanium, untreated nickel-titanium, $\mathrm{N}$ ion implanted $\beta$-titanium, untreated $\beta$-titanium, and stainless steel. All wires were tested under identical conditions in vitro, and the relative tooth movement produced by each type of wire was measured and compared. The results showed that ion implantation of the wires was capable of reducing friction, and allowed the treated wires to produce significantly more tooth movement than their untreated counterparts.

In one of only two clinical studies looking at efficacy, Cobb et al. [62] measured the efficiency of initial alignment in 155 dental arches, with the patients being treated with stainless steel, superelastic $\mathrm{NiTi}$, or ion implanted NiTi archwires. A three-way archwire randomization was completed for optimum results. The ultimate goal was to determine if the ion implantation process had the ability to produce more efficient tooth movement. Patients who were initially determined to have $>5 \mathrm{~mm}$ incisor irregularity participated in this study over the course of 12 months. The degree of anterior irregularity was determined each month for each patient utilizing Little's irregularity index. Ultimately, it was determined that all three wires provided similar initial alignment when re-ligated on a monthly basis, showing no advantage to the ion implantation process for NiTi wires in terms of efficiency of tooth movement.

Kula et al. [63] conducted a "split mouth" design study in which 30 subjects were treated with $\beta$-titanium (TMA) wires, half of which had been ion implanted with nitrogen, the other half remaining in its natural state. At each monthly adjustment appointment, measurements were made to determine the amount of tooth movement achieved on each side of the mouth. Ultimately, they found that there 
was no statistically significant difference in the rates of closure between the implanted and unimplanted sides, thereby concluding that implanted TMA wires cannot enhance space closure.

In conclusion, while ion implanted arch wires have continually been gaining popularity due to their hypothesized reduction in friction, increase in rate of tooth movement and decrease in release of nickel ions, results are often contradictory and thus inconclusive. More clinical testing should be performed to determine with confidence whether surface-treated arch wires have the hypothesized benefits.

\subsection{Coatings in Endodontics}

Endodontic treatment involves the removal of infected nerve tissue within the pulp chamber and canals of the tooth. Due to the small size of the canals, endodontic files are used to shape and clean the canals along with specific chemicals to ensure the disinfection of the canals. Following its introduction to orthodontics, the benefits of NiTi in endodontic applications was first published in 1988 [71]. NiTi's superelastic characteristic allows for greater flexibility and elasticity to that of an ordinary metal/alloy; as a result it has superior ability compared to stainless steel to negotiate root canals without causing undesirable shapes where bacteria may reside. Although NiTi endodontic files show some ideal qualities, after repeated use, increased wear, lower cutting efficiency and reaching a cyclic fatigue limit can be problematic for the practitioner. Surface treatments, including TiN and N ion implantation, have been developed to help control these factors. Figure 2 displays a file that has a titanium nitride coating compared to an uncoated file.

Figure 2. Titanium nitride coated (gold color; left) and uncoated endodontic files.

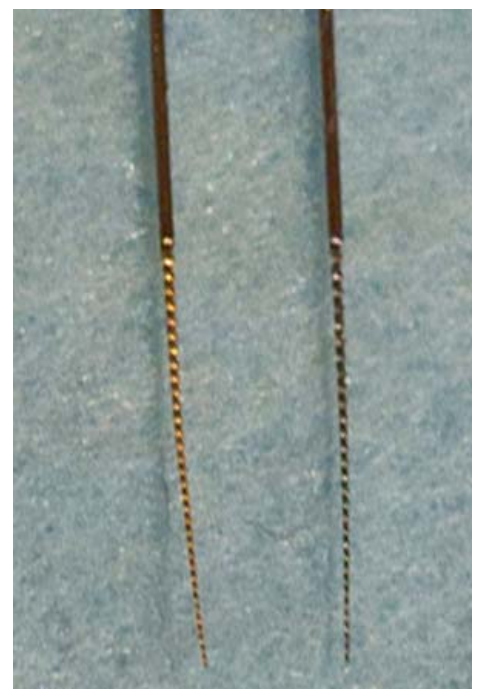

As with other applications, some of the purported advantages associated with surface treatment include increased surface hardness, cutting efficiency, corrosion resistance, and cyclic fatigue resistance. Several studies have supported these statements. Rapisarda et al. [41] found both nitrogen ion implanted and thermally nitride files possessed greater wear resistance and had increased cutting capacity compared to uncoated controls. In a more qualitative study via SEM by the same authors [35], they found nitrogen ion implanted instruments did not manifest the typical signs of wear and surface changes that affected untreated NiTi files when used to instrument acrylic endodontic training blocks. Similarly, Schäfer [17] showed files that had undergone physical vapor deposition had increased 
cutting efficiency compared to uncoated files. Further, repeated sterilization cycles via autoclaving or exposure to sodium hypochlorite prior to sterilization did not alter the cutting efficiency of PVD-coated NiTi files but it did affect the non-coated files [18]. In this study, the greater cutting efficiency of PVD-coated files was noted among the non-sterilized groups. Bonaccorso et al. [7] observed greater pitting potentials of PVD-coated files tested in $\mathrm{NaCl}$, indicating increased corrosion resistance. Gavini et al. [36] observed greater cyclic fatigue lifetimes in NiTi files processed via nitrogen ion implantation.

A potential issue when NiTi is subjected to coating treatments is whether the coating procedure will alter the phase transformation behavior of the files. For this reason, low temperature or even room temperature coating procedures have been advocated and shown to minimally affect phase transformation. Li et al. [34] found phase transformation temperatures and enthalpies between as-received and room temperature plasma immersion ion implantation files were similar, indicating the procedure should not affect superelastic properties.

Not all articles have provided positive results with coating endodontic files. Wolle et al. [37] compared $\mathrm{Ni}$ and Ar ion implanted files for fatigue resistance using curved canals in resin blocks. Results showed that argon implantation moderately improved the performance of the files, but nitrogen implanted files performed worse than uncoated files in the fatigue test. It was theorized that the reduction in file performance was caused by nitrogen diffusion in the grain boundaries, instead of the desired improvement caused by titanium nitride formation. Alves-Claro et al. [32] observed a decrease in hardness for NiTi files following plasma immersion nitrogen ion implantation, although they stated that wear resistance was increased.

Overall, the majority of articles presented suggest TiN coating of endodontic files leads to an increase in beneficial properties without necessarily sacrificing its superelastic qualities. However, it should be noted that these studies have all been in vitro, therefore the clinical success of coated NiTi endodontic instruments remains untested.

\subsection{Coatings in Prosthodontics}

Casting alloys used in dentistry may be bonded to a ceramic (porcelain) system for esthetic restorative purposes. In these systems, the bond between the ceramic material and the alloy relies on the oxide layer between the materials. Careful consideration of the material and methods to improve the oxide layer is required in order to increase the bond strength between the substrates. Although it has its drawbacks, titanium may be used in cast structures in dentistry due to its favorable properties of high strength, good biocompatibility, and corrosion resistance. When looking at titanium bonded to porcelain, the oxide layer can be controlled through the use of surface coatings. TiN coatings have been suggested to control the oxide layer formation and provide a better bond between materials. Oshida and Hashem [30] determined the oxide layer formed on samples coated with TiN resulted in a layer 2.34 times thinner compared to those samples without the coating. This was illustrated as the non-coated samples resulted in an oxide layer of 1-2 $\mu \mathrm{m}$, whereas the TiN coated samples produced an oxide layer of $0.3-0.5 \mu \mathrm{m}$. These results indicate that the application of $\mathrm{TiN}$ as a coating does control the oxide layer. Whether this control over the oxide layer provided better bond strengths was not determined in this study. 
Lim et al. [31] measured the fracture load of crowns using titanium copings and a low fusing porcelain to determine if a TiN coating provides better strength. In addition to a TiN coating, airborne particle abrasion with $\mathrm{Al}_{2} \mathrm{O}_{3}$ and sputter coating with gold were used for comparative surface preparation techniques. Of these, the gold coated titanium, as well as the TiN coated titanium copings, resulted in higher fracture loads than the airborne particle abraded group. This study demonstrated the application of TiN as a coating to titanium does provide strength similar to that of gold-ceramic crowns. Apart from porcelain adherence and strength, fit of a coping or crown is also important. Wu et al. [19] compared the marginal adaptation of a $\mathrm{NiCr}$ base metal alloy with and without a coating via optical microscopy. The TiN coated titanium copings resulted in clinically acceptable marginal adaption $64.86 \%$ of the time, whereas the base metal coping had an acceptance rate of only $47.50 \%$.

Dental magnetic attachments have been used to aid stabilization of removable partial dentures and retention of implant-supported structures. Likewise, TiN coatings have been studied to determine the benefit of application on magnetic stainless steel attachment systems. Traditionally, magnetic stainless steel attachment systems have an undesirable level of corrosion, especially when coupled with other alloys in the oral cavity. The purpose of introducing a TiN coating on magnetic stainless steel has been to reduce corrosion. Hai et al. [13] compared the corrosion rates of a TiN coated magnetic stainless steel attachment system to pure titanium and found it did decrease the level of corrosion. While this study showed a decrease in corrosion of magnetic stainless steel upon application of TiN as a coating, the adhesive capabilities with other materials should also be considered. Taira et al. [14] determined the shear bond strengths of TiN coated magnetic stainless steel and non-coated magnetic stainless steel to two primers and bonding agents and found no significant difference in bond strength between any of the groups and across the materials (coated and non-coated). Therefore, due to the increase in corrosion resistance and equivalent bonding to other substrates, it may be suggested that TiN coated magnetic stainless steel should be used over non-coated magnetic stainless steel attachments. Titanium nitride coatings have since been further investigated in bonding with resin composites when applied to $\mathrm{Au}-\mathrm{Pd}-\mathrm{Ag}$ alloys, as in the case of a resin-veneered crown. Tanaka et al. [26] examined the shear bond strength of TiN coatings on Au-Pd-Ag alloys when bonded to composite resin with a metal primer. The results from this study showed an increase in bond strength for groups with a TiN coating on the alloy compared to the non-coated group.

Throughout the TiN coating prosthodontics literature, most research has demonstrated benefits for application of the coating. These benefits range from increases in physical properties to decreases in the amount of corrosion. Biocompatibility of the TiN coating to its oral surroundings is also very important clinically. Chien et al. [27] evaluated the cytotoxicity of nickel-based alloy surfaces after nitride film coatings of TiN and TiAlN. At $3 \mathrm{~h}$, human fibroblast cells began to spread across all test surfaces, but at $24 \mathrm{~h}$, the coated groups were significantly higher in cell proliferation and viability than polished and control Ni-alloy surfaces. Thus, the biocompatibility of this nickel-based alloy increased significantly after the application of TiN and TiAlN coatings.

Better marginal adaptation was found clinically with the application of TiN coating on titanium. For magnetic stainless steel alloys, better corrosion resistance and adequate bond strengths were found with the application of $\mathrm{TiN}$ as a coating. In addition, TiN coatings on $\mathrm{Au}-\mathrm{Pd}-\mathrm{Ag}$ alloys did increase the bond strength to composite resin and the coating of TiN to a nickel-based alloy improved 
biocompatibility. Overall, with all of these benefits in mind, it is clear that many dental alloys have marked improvements with the application of TiN coatings.

\subsection{Coatings in Dental Instrumentation}

Periodontal therapy includes the removal of hard and soft deposits from root surfaces. As a result, many dental instruments used in oral hygiene control must be sufficiently hard and resistant to wear and dulling. Naturally, coating dental instruments with titanium nitride coatings has been investigated as a means of developing instruments with better edge retention. Sisera et al. [64] compared TiN coated curettes to a cryogenically treated stainless steel instrument and uncoated stainless steel control in a study involving root planing of bovine teeth. All three materials held their cutting capacity for up to 1010 strokes, however, sterilization of the instruments was found to decrease cutting edge retention. Clinically, the cutting efficacy of the curettes is important for removal of subgingival biofilm, calculus, and endotoxins from the root surface. Aspriello et al. [65] showed the use of a curette followed by a TiN coated ultrasonic instrument created root surfaces free from smear layers, which presumably would promote early wound healing. Sawase et al. [42] measured surface hardness and abrasion resistance of different hygiene instruments, some with a TiN coating. The TiN coated titanium possessed a hardness approximately twelve times that of non-coated titanium. Further, abrasion resistance was greater in the TiN coated group compared to pure titanium.

Certain dental instruments are used to place restorative materials and may be used mechanically but may also contact restorative materials. Thus, titanium nitride has been researched as a coating to stainless steel dental instruments to improve properties of adhesion of the restorative material, contamination and discoloration of the restorative material, and wear resistance [66]. With regard to adhesion of restorative materials, TiN coatings have been suggested and marketed to be low-stick and improve this quality over traditional stainless steel instruments due to its low coefficient of friction and higher contact angle. For composite resins and glass ionomers, TiN coated stainless steel instruments produced no decrease in adhesion compared to non-coated, clean, polished stainless steel instruments. When considering discoloration of the restorative material, TiN coated stainless steel instruments produced no discoloration of the restoration, whereas non-coated stainless steel instruments did discolor composite resin samples [66]. When compared with non-coated stainless steel instruments, TiN coated instruments had better wear resistance to unpolymerized composite resin [67]. Further, this coating was shown to be harder, smoother and uncracked compared to alumina coated stainless steel instruments and non-coated stainless steel instruments after sterilization and ultrasonic cleaning cycles. In order to improve wear resistance of tungsten carbide (WC-Co) instruments, TiN has been suggested as an interlayer prior to diamond deposition on these dental instruments. In this case, TiN acts as a diffusion barrier between cobalt and carbon species to increase the adhesion of diamond films which are desired for their wear resistance [68]. When compared to tungsten carbide instruments without an interlayer of TiN, the instruments with TiN present increased the lifetime of the instrument and had better wear resistance [68]. 


\section{Conclusions}

Titanium nitride and/or nitrogen ion implanted coated dental materials have been investigated within many different dental disciplines for a few decades. Despite this, commercially-available materials primarily consist of coated orthodontic archwires. Though much research has determined the effect of the coatings on hardness, wear resistance, corrosion, friction, bone adaption, and bacterial adherence, very few clinical studies are available to ascertain their effectiveness in vivo.

\section{Acknowledgments}

The authors thank Neill H. Luebke and the Ormco Corporation for providing the coated endodontic file and orthodontic wires, respectively, displayed in the figures.

\section{References}

1. Mezger, P.R.; Creugers, N.H. Titanium nitride coatings in clinical dentistry. J. Dent. 1992, 20, 342-344.

2. Scarano, A.; Piattelli, M.; Vrespa, G.; Caputi, S.; Piattelli, A. Bacterial adhesion on titanium nitride-coated and uncoated implants: An in vivo human study. J. Oral Implant. 2003, 29, 80-85.

3. Durual, S.; Pernet, F.; Rieder, P.; Mekki, M.; Cattani-Lorente, M.; Wiskott, H.W. Titanium nitride oxide coating on rough titanium stimulates the proliferation of human primary osteoblasts. Clin. Oral Implant. Res. 2011, 22, 552-559.

4. Annunziata, M.; Guida, L.; Perillo, L.; Aversa, R.; Passaro, I.; Oliva, A. Biological response of human bone marrow stromal cells to sandblasted titanium nitride-coated implant surfaces. J. Mater. Sci. Mater. Med. 2008, 19, 3585-3591.

5. Scarano, A.; Piattelli, M.; Vrespa, G.; Petrone, G.; Iezzi, G.; Piattelli, A. Bone healing around titanium and titanium nitride-coated dental implants with three surfaces: An experimental study in rats. Clin. Implant Dent. Relat. Res. 2003, 5, 103-111.

6. Burstone, C.J.; Farzin-Nia, F. Production of low-friction and colored TMA by ion implantation. J. Clin. Orthod. 1995, 29, 453-461.

7. Bonaccorso, A.; Tripi, T.R.; Rondelli, G.; Condorelli, G.G.; Cantatore, G.; Schäfer, E. Pitting corrosion resistance of nickel-titanium rotary instruments with different surface treatments in seventeen percent ethylenediaminetetraacetic acid and sodium chloride solutions. J. Endod. 2008, 34, 208-211.

8. Yoshinari, M.; Oda, Y.; Kato, T.; Okuda, K. Influence of surface modifications to titanium on antibacterial activity in vitro. Biomaterials 2001, 22, 2043-2048.

9. Yoshinari, M.; Oda, Y.; Kato, T.; Okuda, K.; Hirayama, A. Influence of surface modifications to titanium on oral bacterial adhesion in vitro. J. Biomed. Mater. Res. 2000, 2, 388-394.

10. Satomi, K.; Akagawa, Y.; Nikai, H.; Tsuru, H. Tissue response to implanted ceramic-coated titanium alloys in rats. J. Oral Rehabil. 1988, 15, 339-345.

11. Kao, C.T.; Guo, J.U.; Huang, T.H. Comparison of friction force between corroded and noncorroded titanium nitride plating of metal brackets. Am. J. Orthod. Dentofac. Orthoped. 2011, 139, 594-600. 
12. Kao, C.T.; Ding, S.J.; Chen, Y.C.; Huang, T.H. The anticorrosion ability of titanium nitride (TiN) plating on an orthodontic metal bracket and its biocompatibility. J. Biomed. Mater. Res. 2002, 63, 786-792.

13. Hai, K.; Sawase, T.; Matsumura, H.; Atsuta, M.; Baba, K.; Hatada, R. Corrosion resistance of a magnetic stainless steel ion-plated with titanium nitride. J. Oral Rehabil. 2000, 27, 361-366.

14. Taira, Y.; Hai, K.; Matsumura, H.; Atsuta, M. Adhesive bonding of titanium nitride-plated stainless steel for magnetic attachments. Eur. J. Oral Sci. 2001, 109, 204-207.

15. Mengel, R.; Meer, C.; Flores-de-Jacoby, L. The treatment of uncoated and titanium nitride-coated abutments with different instruments. Int. J. Oral Maxillofac. Implant. 2004, 19, 232-238.

16. Annunziata, M.; Oliva, A.; Basile, M.A.; Giordano, M.; Mazzola, N.; Rizzo, A.; Lanza, A.; Guida, L. The effects of titanium nitride-coating on the topographic and biological features of TPS implant surfaces. J. Dent. 2011, 39, 720-728.

17. Schäfer, E. Effect of physical vapor deposition on cutting efficiency of nickel-titanium files. J. Endod. 2002, 28, 800-802.

18. Schäfer, E. Effect of sterilization on the cutting efficiency of PVD-coated nickel-titanium endodontic instruments. Int. Endod. J. 2002, 35, 867-872.

19. Wu, J.C.; Lai, L.C.; Sheets, C.G.; Earthman, J.; Newcomb, R. A comparison of the marginal adaptation of cathode-arc vapor-deposited titanium and cast base metal copings. J. Prosthet. Dent. 2011, 105, 403-409.

20. Chung, K.H.; Duh, J.G.; Shin, D.; Cagna, D.R.; Cronin, R.J., Jr. Characteristics and porcelain bond strength of (Ti,Al)N coating on dental alloys. J. Biomed. Mater. Res. 2002, 63, 516-521.

21. Kurt, M.; Külünk, T.; Ural, C.; Külünk, S.; Danişman, S.; Savaş, S. The effect of different surface treatments on retention of cement retained implant supported restorations. J. Oral Implant. 2010, doi:http://dx.doi.org/10.1563/AAID-JOI-D-10-00151.

22. Grössner-Schreiber, B.; Griepentrog, M.; Haustein, I.; Müller, W.D.; Lange, K.P.; Briedigkeit, H.; Göbel, U.B. Plaque formation on surface modified dental implants: An in vitro study. Clin. Oral Implant. Res. 2001, 12, 543-551.

23. Groessner-Schreiber, B.; Hannig, M.; Dück, A.; Griepentrog, M.; Wenderoth, D.F. Do different implant surfaces exposed in the oral cavity of humans show different biofilm compositions and activities? Eur. J. Oral Sci. 2004, 112, 516-522.

24. Groessner-Schreiber, B.; Neubert, A.; Müller, W.D.; Hopp, M.; Griepentrog, M.; Lange, K.P. Fibroblast growth on surface-modified dental implants: An in vitro study. J. Biomed. Mater. Res. A 2003, 64, 591-599.

25. Grössner-Schreiber, B.; Herzog, M.; Hedderich, J.; Dück, A.; Hannig, M.; Griepentrog, M. Focal adhesion contact formation by fibroblasts cultured on surface-modified dental implants: An in vitro study. Clin. Oral Implant. Res. 2006, 17, 736-745.

26. Tanaka, K.; Kimoto, K.; Sawada, T.; Toyoda, M. Shear bond strength of veneering composite resin to titanium nitride coating alloy deposited by radiofrequency sputtering. J. Dent. 2006, 34, 277-282.

27. Chien, C.C.; Liu, K.T.; Duh, J.G.; Chang, K.W.; Chung, K.H. Effect of nitride film coatings on cell compatibility. Dent. Mater. 2008, 24, 986-993. 
28. Tripi, T.R.; Bonaccorso, A.; Rapisarda, E.; Tripi, V.; Condorelli, G.G.; Marino, R.; Fragalà, I. Depositions of nitrogen on NiTi instruments. J. Endod. 2002, 28, 497-500.

29. Endo, K.; Sachdeva, R.; Araki, Y.; Ohno, H. Effects of titanium nitride coatings on surface and corrosion characteristics of Ni-Ti alloy. Dent. Mater. J. 1994, 13, 228-239.

30. Oshida, Y.; Hashem, A. Titanium-porcelain system Part I: Oxidation kinetics of nitrided pure titanium, simulated to porcelain firing process. Biomed. Mater. Eng. 1993, 3, 185-198.

31. Lim, H.P.; Kim, J.H.; Lee, K.M.; Park, S.W. Fracture load of titanium crowns coated with gold or titanium nitride and bonded to low-fusing porcelain. J. Prosthet. Dent. 2011, 10, 164-170.

32. Alves-Claro, A.P.; Claro, F.A.; Uzumaki, E.T. Wear resistance of nickel-titanium endodontic files after surface treatment. J. Mater. Sci. Mater. Med. 2008, 19, 3273-3277.

33. Iijima, M.; Yuasa, T.; Endo, K.; Muguruma, T.; Ohno, H.; Mizoguchi, I. Corrosion behavior of ion implanted nickel-titanium orthodontic wire in fluoride mouth rinse solutions. Dent. Mater. J. 2010, 29, 53-58.

34. Li, U.M.; Iijima, M.; Endo, K.; Brantley, W.A.; Alapati, S.B.; Lin, C.P. Application of plasma immersion ion implantation for surface modification of nickel-titanium rotary instruments. Dent. Mater. J. 2007, 26, 467-473.

35. Rapisarda, E.; Bonaccorso, A.; Tripi, T.R.; Fragalk, I.; Condorelli, G.G. The effect of surface treatments of nickel-titanium files on wear and cutting efficiency. Oral Surg. Oral Med. Oral Pathol. Oral Radiol. Endod. 2000, 89, 363-368.

36. Gavini, G.; Pessoa, O.F.; Barletta, F.B.; Vasconcellos, M.A.; Caldeira, C.L. Cyclic fatigue resistance of rotary nickel-titanium instruments submitted to nitrogen ion implantation. J. Endod. 2010, 36, 1183-1186.

37. Wolle, C.F.; Vasconcellos, M.A.; Hinrichs, R.; Becker, A.N.; Barletta, F.B. The effect of argon and nitrogen ion implantation on nickel-titanium rotary instruments. J. Endod. 2009, 35, 1558-1562.

38. Catledge, S.A.; Vohra, Y.K.; Bellis, S.L.; Sawyer, A.A. Mesenchymal stem cell adhesion and spreading on nanostructured biomaterials. J. Nanosci. Nanotechnol. 2004, 4, 986-989.

39. De Maeztu, M.A.; Alava, J.I.; Gay-Escoda, C. Ion implantation: Surface treatment for improving the bone integration of titanium and Ti6Al4V dental implants. Clin. Oral Implant. Res. 2003, 14, $57-62$.

40. Kusy, R.P.; Tobin, E.J.; Whitley, J.Q.; Sioshansi, P. Frictional coefficients of ion-implanted alumina against ion-implanted beta-titanium in the low load, low velocity, single pass regime. Dent. Mater. 1992, 8, 167-172.

41. Rapisarda, E.; Bonaccorso, A.; Tripi, T.R.; Condorelli, G.G.; Torrisi, L. Wear of nickel-titanium endodontic instruments evaluated by scanning electron microscopy: Effect of ion implantation. J. Endod. 2001, 27, 588-592.

42. Sawase, T.; Yoshida, K.; Taira, Y.; Kamada, K.; Atsuta, M.; Baba, K. Abrasion resistance of titanium nitride coatings formed on titanium by ion-beam-assisted deposition. J. Oral Rehabil. 2005, 32, 151-157.

43. Tamura, Y.; Yokoyama, A.; Watari, F.; Kawasaki, T. Surface properties and biocompatibility of nitrided titanium for abrasion resistant implant materials. Dent. Mater. J. 2002, 21, 355-372. 
44. Gil, F.J.; Solano, E.; Campos, A.; Boccio, F.; Sáez, I.; Alfonso, M.V.; Planell, J.A. Improvement of the friction behaviour of NiTi orthodontic archwires by nitrogen diffusion. Biomed. Mater. Eng. 1998, 8, 335-342.

45. Gil, F.J.; Solano, E.; Mendoza, A.; Pena, J. Inhibition of Ni release from NiTi and NiTiCu orthodontic archwires by nitrogen diffusion treatment. J. Appl. Biomater. Biomech. 2004, 2, 151-155.

46. Tripi, T.R.; Bonaccorso, A.; Condorelli, G.G. Fabrication of hard coatings on NiTi instruments. J. Endod. 2003, 29, 132-134.

47. Alsabeeha, N.H.; Swain, M.V.; Payne, A.G. Clinical performance and material properties of single-implant overdenture attachment systems. Int. J. Prosthodont. 2011, 24, 247-254.

48. Yi, K.J.; Kim, S.G.; Moon, S.Y.; Lim, S.C.; Son, J.S.; Kim, C.G.; Chung, K. Vertical distraction osteogenesis using a titanium nitride-coated distractor. Oral Surg. Oral Med. Oral Pathol. Oral Radiol. Endod. 2009, 107, e5-e9.

49. Abi Nader, S.; de Souza, R.F.; Fortin, D.; de Koninck, L.; Fromentin, O.; Albuquerque, R.F., Jr. Effect of simulated masticatory loading on the retention of stud attachments for implant overdentures. J. Oral Rehabil. 2011, 38, 157-164.

50. Assunção, W.G.; Delben, J.A.; Tabata, L.F.; Barão, V.A.; Gomes, E.A.; Garcia, I.R., Jr. Preload evaluation of different screws in external hexagon joint. Implant Dent. 2012, 21, 46-50.

51. Wichelhaus, A.; Geserick, M.; Hibst, R.; Sander, F.G. The effect of surface treatment and clinical use on friction in NiTi orthodontic wires. Dent. Mater. 2005, 21, 938-945.

52. D’Antò, V.; Rongo, R.; Ametrano, G.; Spagnuolo, G.; Manzo, P.; Martina, R.; Paduano, S.; Valletta, R. Evaluation of surface roughness of orthodontic wires by means of atomic force microscopy. Angle Orthod. 2012, doi:http://dx.doi.org/10.2319/100211-620.1.

53. Husmann, P.; Bourauel, C.; Wessinger, M.; Jäger, A. The frictional behavior of coated guiding archwires. J. Orofac. Orthop. 2002, 63, 199-211.

54. Kusy, R.P.; Whitley, J.Q.; de Araújo Gurgel, J. Comparisons of surface roughnesses and sliding resistances of 6 titanium-based or TMA-type archwires. Am. J. Orthod. Dentofac. 2004, 126, 589-603.

55. Cash, A.; Curtis, R.; Garrigia-Majo, D.; McDonald, F. A comparative study of the static and kinetic frictional resistance of titanium molybdenum alloy archwires in stainless steel brackets. Eur. J. Orthodont. 2004, 26, 105-111.

56. Neumann, P.; Bourauel, C.; Jäger, A. Corrosion and permanent fracture resistance of coated and conventional orthodontic wires. J. Mater. Sci. Mater. Med. 2002, 13, 141-147.

57. Peitsch, T.; Klocke, A.; Kahl-Nieke, B.; Prymak, O.; Epple, M. The release of nickel from orthodontic NiTi wires is increased by dynamic mechanical loading but not constrained by surface nitridation. J. Biomed. Mater. Res. A 2007, 82, 731-739.

58. Kim, H.; Johnson, J.W. Corrosion of stainless steel, nickel-titanium, coated nickel-titanium, and titanium orthodontic wires. Angle Orthod. 1999, 69, 39-44.

59. Schuster, G.; Reichle, R.; Bauer, R.R.; Schopf, P.M. Allergies induced by orthodontic alloys: Incidence and impact on treatment-Results of a survey in private orthodontic offices in the Federal State of Hesse, Germany. J. Orofac. Orthop. 2004, 65, 48-59. 
60. Pernier, C.; Grosgogeat, B.; Ponsonnet, L.; Benay, G.; Lissac, M. Influence of autoclave sterilization on the surface parameters and mechanical properties of six orthodontic wires. Eur. J. Orthodont. 2005, 27, 72-81.

61. Ryan, R.; Walker, G.; Freeman, K.; Cisneros, G.J. The effects of ion implantation on rate of tooth movement: An in vitro model. Am. J. Orthod. Dentofac. 1997, 112, 64-68.

62. Cobb, N.W.; Kula, K.S.; Phillips, C.; Proffit, W.R. Efficiency of multi-strand steel, superelastic $\mathrm{Ni}-\mathrm{Ti}$ and ion-implanted Ni-Ti archwires for initial alignment. Clin. Orthod. Res. 1998, 1, 12-19.

63. Kula, K.; Phillips, C.; Gibilaro, A.; Proffit, W.R. Effect of ion implantation of TMA archwires on the rate of orthodontic sliding space closure. Am. J. Orthod. Dentofac. 1998, 114, 577-580.

64. Sisera, M.; Hofer, D.J.; Sener, B.; Attin, T.; Schmidlin, P.R. In vitro evaluation of three curettes with edge retention technology after extended use. Schweiz Monatsschr Zahnmed. 2009, 119, $1200-1208$.

65. Aspriello, S.D.; Piemontese, M.; Levrini, L.; Sauro, S. Ultramorphology of the root surface subsequent to hand-ultrasonic simultaneous instrumentation during non-surgical periodontal treatments: An in vitro study. J. Appl. Oral Sci. 2011, 19, 74-81.

66. Steele, J.G.; McCabe, J.F.; Barnes, I.E. Properties of a titanium nitride coating for dental instruments. J. Dent. 1991, 19, 226-229.

67. Rawlings, R.D.; Robinson, P.B.; Rogers, P.S. The durability of ceramic coated dental instruments. Eur. J. Prosthodont. Restor. Dent. 1995, 3, 211-216.

68. Jackson, M.J.; Sein, H.; Ahmed, W.; Woodwards, R. Novel diamond-coated tools for dental drilling applications. J. Med. Eng. Technol. 2007, 31, 81-93.

69. Andreasen, G.F.; Hilleman, T.B. An evaluation of 55 cobalt substituted Nitinol wire for use in orthodontics. J. Am. Dent. Assoc. 1971, 82, 1373-1375.

70. Goldberg, J.; Burstone, C.J. An evaluation of beta titanium alloys for use in orthodontic appliances. J. Dent. Res. 1979, 58, 593-599.

71. Walia, H.; Brantley, W.A.; Gerstein, H. An initial investigation of the bending and torsional properties of Nitinol root canal files. J. Endod. 1988, 14, 346-351.

(C) 2012 by the authors; licensee MDPI, Basel, Switzerland. This article is an open access article distributed under the terms and conditions of the Creative Commons Attribution license (http://creativecommons.org/licenses/by/3.0/). 